\title{
Manifestaciones radiológicas de leucemia linfoide aguda en niños
}

\author{
Radiologic manifestations of acute lymphoid leukemia in children
}

Edgar Cabrera1, Isabel Sarmiento1,2, Rubén Montoya1,2, Gloria Uribe¹, Edna Quintero1, Johnny García²

${ }^{1}$ Fundación HOMI Hospital La Misericordia.

${ }^{2}$ Universidad Nacional de Colombia.

Se presenta el caso de una paciente de género femenino de 9 años de edad, quien ingresa a institución de cuarto nivel de complejidad en marzo de 2016. Manifiesta cuadro clínico de 1 día de evolución, consistente en dolor torácico no traumático de moderada intensidad que se exacerba con la respiración. Asintomática hasta 6 semanas antes de la consulta cuando aparecen artralgias y mialgias migratorias, especialmente a nivel de caderas con limitación para la marcha; astenia, adinamia y pérdida de peso, aproximadamente $6 \mathrm{~kg}$, sin fiebre ni sudoración nocturna. Consultó en varias oportunidades, le tomaron estudio radiográfico ( $\mathrm{Rx}$ de rodillas) aparentemente normal y, finalmente, formularon analgésicos y órdenes de terapia física, sin mejoría alguna.

Al examen físico de ingreso, en regulares condiciones generales. Peso: $19 \mathrm{~kg}$ (<P3). Talla: $124 \mathrm{~cm}$ (-1 DS). Signos vitales: FR 20x', FC $80 x$. Palidez mucocutánea leve, sin deshidratación, sin signos de dificultad respiratoria. Adenopatías cervicales e inguinales múltiples $<1 \mathrm{~cm}$ de diámetro. Dolor a nivel de estructuras óseas (clavícula izquierda y región paraesternal derecha), sin visceromegalias, sin lesiones cutáneas. Resto de examen físico sin alteraciones. Se toman laboratorios: hemograma leucocitos: 6,6 k/l, N: 68\% (4.495 absolutos), L: 11\% (727 absolutos), M: $2 \%$, blastos: $17 \%$. Hb: 9,4 g/dl, Hcto.: 29,3\%, HCM: 27,2, VCM: 84,9. Plaq.: 316 x10\%/l. Extendido de sangre periférica: policromasia, anisocitosis, macrocitosis, granulaciones tóxicas. Leucocitos normales en número, presencia de blastos. Plaquetas normales en número y morfología.

Con la sospecha de clínica de leucemia aguda y hallazgos de blastos en sangre periférica es hospitalizada, se inicia estudio con exámenes complementarios: función renal y electrolitos normales. Ácido úrico: 4,9. LDH: 321. Ecografía abdominal total: hígado con longitud en el límite superior, sin otras alteraciones. Radiografía de tórax sin masas mediastinales. Radiografía de rodillas con lesiones líticas poliostóticas bilaterales y lesiones líticas con apolillado en tibias y peronés (figura 1), en el TAC de pelvis se encuentran lesiones densas en fémur (figura 2). Se realiza aspirado-biopsia de médula ósea, procedimiento difícil, seco. El informe preliminar de mielograma mostró células de aspecto inmaduro vacuoladas, sugiriendo origen neoplásico, no leucémicas (figura 3); la biopsia de médula ósea evidenció infiltración masiva por neoplasia indiferenciada probablemente de origen hematolinfoide, se solicitaron estudios de inmunohistoquímica para la biopsia que confirman linaje hematolinfoide, compromiso por leucemia linfoide aguda de precursores $B$, severo aumento de retículo con tinción de reticulina (figuras $4 a$ y $4 b$ ). Otros estudios: traslocación 9;22 negativa, cariotipo $44 X X$, con ausencia del cromosoma 5, imagen de monosomia de los cromosomas 14-20 y una tercera imagen presentó un cariotipo hiperdiploide cercano a la triploidía. Citológico de LCR primera intratecal negativo para neoplasia hematolinfoide. Se revisó en conjunto el caso con patología por hallazgos de mielofibrosis en la biopsia inicial que disminuyeron hasta casi desaparecer en la biopsia de evaluación del día 15 y del final de inducción. Se consideraron los hallazgos como cambios de mielofibrosis relacionados con leucemia linfoide aguda.

Derechos de reproducción: @ 2016 Cabrera et al. Este es un artículo de acceso libre distribuido bajo los términos de la licencia Creative Commons BY-NC-ND, la cual otorga permiso público para compartir y usar los artículos bajo la condición de atribución al autor, no modificación de su contenido y no uso con fines comerciales.

Este artículo debe citarse como Cabrera E, Sarmiento I, Montoya R, Uribe G, Quintero E, García J. Manifestaciones radiológicas de leucemia linfoide aguda en niños. Revista Colombiana de Hematología y Oncología. 2016;3(2):36-38. 

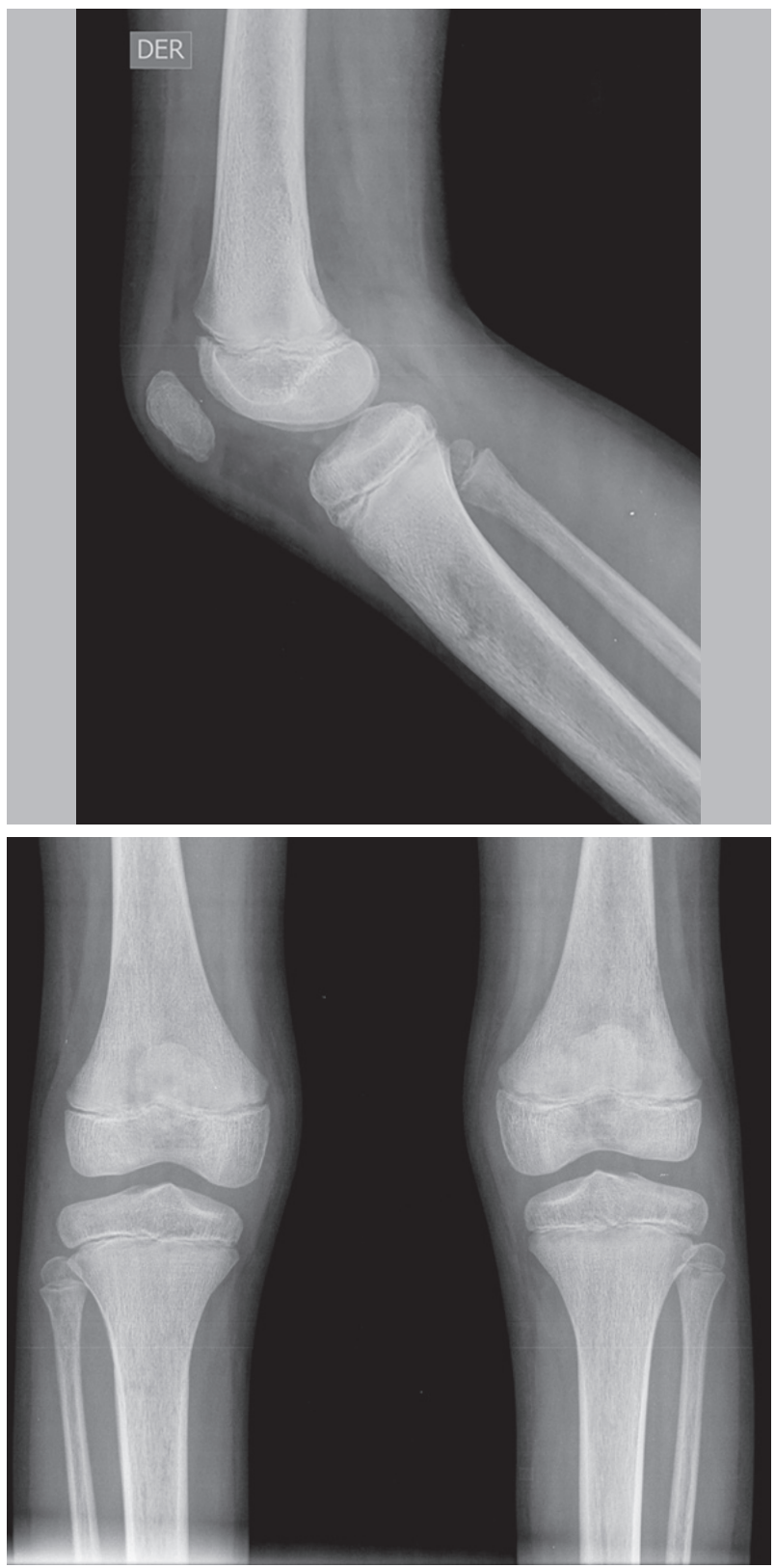

Figura 1. Radiografías frontal y lateral comparativas de rodillas, donde se observan lesiones líticas mal definidas, con un patrón apolillado metafisiario distal de fémures y proximal de tibias y peronés.

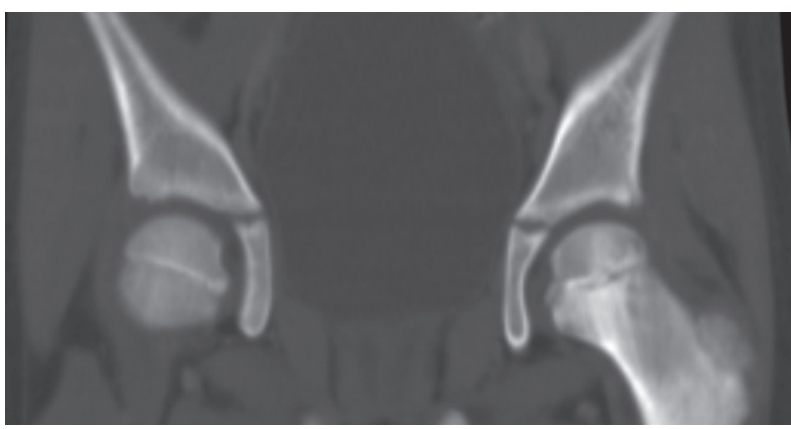

Figura 2. Tomografía axial computarizada de cadera, en reconstrucción coronal, donde se observa lesión densa en la epífisis y metáfisis proximal del fémur izquierdo.

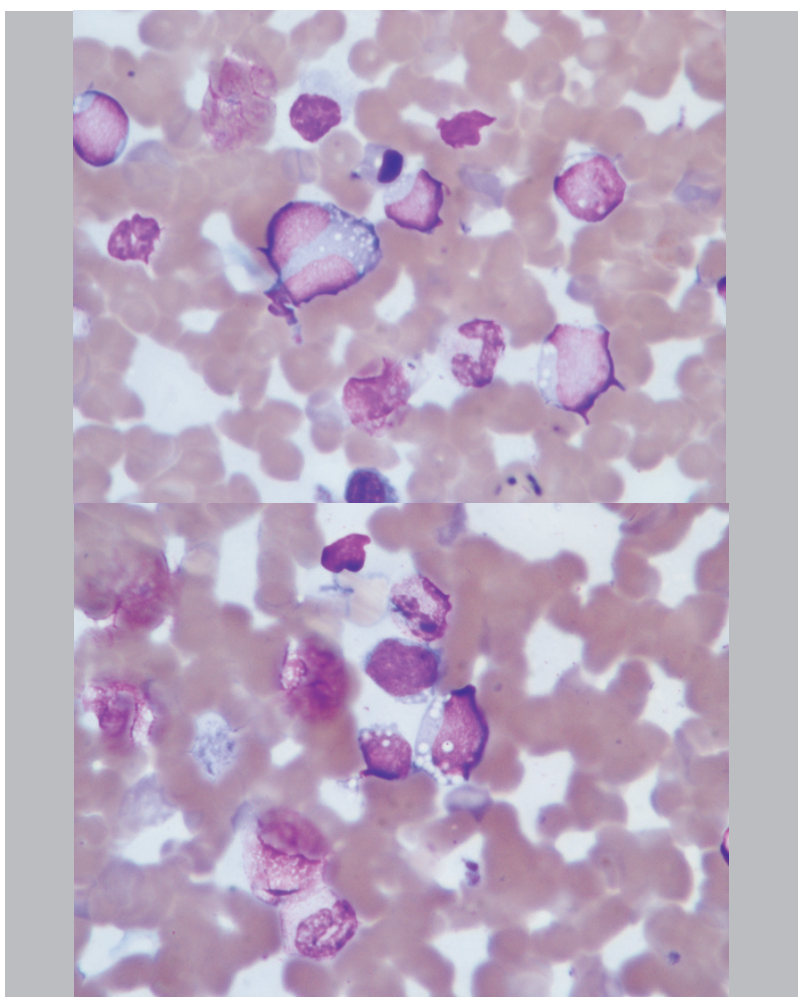

Figura 3. Mielograma con tinción de Wright, con infiltración por células de aspecto tumoral no hematolinfoides en su morfología. Imagen 40X.

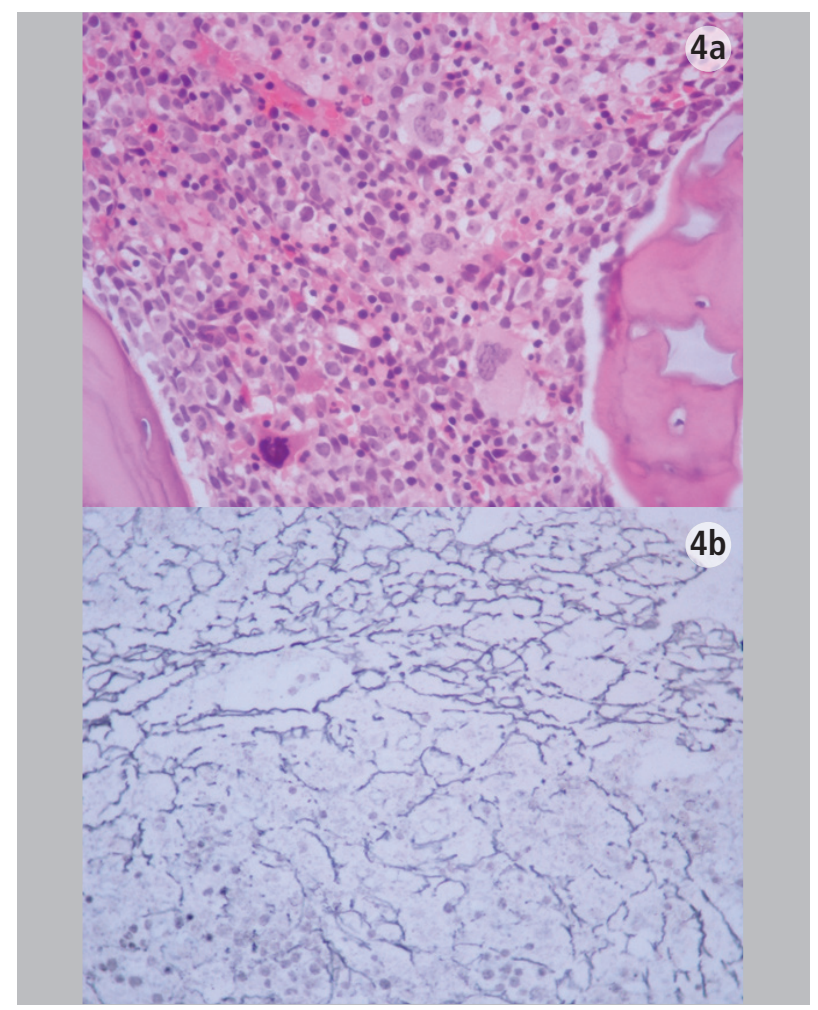

Figuras 4a y 4b. (4a) Con tinción H\&E: médula ósea masivamente infiltrada por una población de células neoplásicas de tamaño mediano, algunas con citoplasma evidente claro, núcleos moldeados de cromatina fina con nucléolos prominentes; otras muestran un aspecto más hipercromático. (4b) Hay severo incremento de la trama reticulínica. Imagen (1) H\&E 40X. Imagen (2) histoquímica retículo 40X. 


\section{Discusión}

La leucemia linfoide aguda (LLA) es la neoplasia más frecuente en los niños, los hallazgos de lesiones óseas pueden preceder a las pruebas de laboratorio confirmatorias del diagnóstico; por esta razón, conocer esta presentación de la enfermedad es muy importante para el diagnóstico oportuno. Estas características radiológicas se pueden encontrar en más del $50 \%$ de los pacientes y pueden ser diversas: osteólisis, bandas metafisarias, osteopenia, osteosclerosis, patrón permeativo, fracturas patológicas, reacción perióstica y lesiones mixtas de lisis y esclerosis ${ }^{1-4}$.

Las lesiones óseas son más frecuentes en niños que en adultos, más usuales en leucemia linfoide aguda que en mieloide aguda, no tienen mal pronóstico en comparación con los pacientes sin lesiones óseas. El diagnóstico diferencial de estos hallazgos es el neuroblastoma, patología cuyo cuadro clínico puede ser similar a una leucemia aguda.

Otro hallazgo importante de esta paciente es la morfología del mielograma inicial que no es característica de blastos linfoides; en la biopsia se considera que la infiltración masiva que hay puede ser hematoinfoide y además anotan la presencia de mielofibrosis; el material no fue adecuado para procesamiento de citometría de flujo. La mielofibrosis está descrita como hallazgo al diagnóstico de leucemia linfoide aguda de precursores $B$, mucho más frecuente que en $T$, no es claro su significado en relación con el pronóstico, algunos autores han intentado conferirle peor pronóstico, otros consideran que debe estudiarse a fondo si existe o no relación ${ }^{5}$.

\section{Referencias}

1. Shahnazi M, Khatami A, Shamsian B, Haerizadeh B, Mehrafarin M. Bony lesions in pediatric acute leukemia: pictorial essay. Iran J Radiol 2012;9(1):50-6.

2. Sinigaglia R, Gigante C, Bisinella G, Varotto S, Zanesco L, Turra S. Musculoskeletal manifestations in pediatric acute leukemia. J Pediatr Orthop 2008;28(1):20-8.

3. Barbosa CM, Nakamura C, Terreri MT, Lee ML, Petrilli AS, Hilario $\mathrm{MO}$. Musculoskeletal manifestations as the onset of acute leukemias in childhood. J Pediatr (Rio J) 2002;78(6):481-4.

4. Guillerman RP, Voss SD, Parker BR. Leukemia and lymphoma. Radiol Clin North Am 2011;49(4):767-97.

5. Norén-Nyström $U$, Roos $G$, Bergh A, Botling J, Lönnerholm G, Porwit $A$, et al. Bone marrow fibrosis in childhoood acute lymphoblastic leukemia correlates to biological factors, treatment response and outcome. Leukemia 2008;22(3):504-10. 